\begin{abstract}
Understanding individual variability in sexual boredom may offer relevant insights for the study of sexuality. The aim of this study was to determine whether there were distinct groups of men and women experiencing sexual boredom and how those groups differed in other aspects of sexuality. Sample consisted of 1021 participants aged 18 to 75 years old $(M=32.68, S D=8.79)$. A gender-stratified cluster analysis was used for classifying the subgroups based on the extent of our variables of interest, and Analysis Of Variance (ANOVA) and chi-square of association tests were carried out to examine potential differences on demographics per group. Cluster analysis revealed a threecluster solution for both men and women. Men grouped into low sexual boredom, high sexual boredom with high sexual motivation, and high sexual boredom with low sexual motivation. Women grouped into low sexual boredom, moderate sexual boredom, and high sexual boredom. Cluster analyses revealed, the groups of men and women with low sexual boredom presented low boredom proneness, low sexual motivation (sexual desire and excitation), and high hedonic value (sexual pleasure and sexual satisfaction). The group of men with high sexual boredom with high sexual motivation and the group of women with moderate sexual boredom displayed high sexual sensation seeking, high sexual motivation, and high hedonic value. The group of men and the group of women dealing with high sexual boredom, presented high boredom proneness, low sexual motivation, and low hedonic value. These findings have implications for couples dealing with sexual problems and, potentially, for sexual risk taking. Keywords: sexual boredom, sexual desire, sexual excitation, sexual satisfaction, sexual pleasure, cluster analysis
\end{abstract}


Sexual boredom, sexual motivation, and hedonic value: A cluster analysis

Sexual boredom is a dimension of general boredom that was previously correlated with other variables of human sexuality, namely sexual desire, and sexual satisfaction, but without offering much understanding of the nature of this construct. Additional knowledge on how different levels of boredom and sexual boredom relate with aspects of motivation and enjoyment of sex may offer relevant insights for the study of sexuality.

\section{Boredom and sexual boredom}

Boredom proneness is the tendency toward experiencing boredom (Farmer \& Sundberg, 1986), a fleeting psychological state (e.g. Chaney \& Chang, 2005; Fahlman, Mercer-Lynn, Flora, \& Eastwood, 2013; Leary, Rogers, Canfield, \& Coe, 1986) that takes place when the environment is perceived as unstimulating, repetitive, or monotonous (Hill \& Perkins, 1985; Mikulas \& Vodanovich, 1993; Perkins \& Hill, 1985; Zuckerman, 1979). There seem to be two main sources of boredom: low levels of perceived environmental stimulation, or external stimulation, and inability to create interesting activities for oneself, or internal stimulation (e.g. Bruursema, Kessler, \& Spector, 2011; Gana \& Akremi, 1998; Vodanovich \& Kass, 1990). In addition, research also identified some consequences of experiencing boredom, including decreases in judged hedonic value (Berlyne, 1970), behavioral purposelessness (Fenichel, 1951), or, contrarily, sensation seeking behaviors, disinhibition (e.g. Zuckerman, 1979), and impulsiveness (Moynihan, Igou, \& van Tilburg, 2017).

Sexual boredom was first defined as the tendency to experience boredom with the sexual aspects of life, including sexual monotony (sexual routine and tedium) and sexual stimulation (aspects of sexual excitement and constraint) (Watt \& Ewing, 1996). Later, sexual boredom was defined as boredom with boring sex, i.e. dull, routine and 
over-rehearsed sex, by twelve men in a qualitative study (Tunariu \& Reavey, 2003). In these men's views, sexual boredom was an emotion characterized by indifference or demotivation towards a sexual partner in the context of long-term sexually exclusive relationships. Another study by the same authors with men and women in long-term relationships found participants recognized sexual boredom in their relationships when sex was no longer pleasing, when there was sexual disinterest or no enthusiasm for sex, or if felt a strong extra-dyadic focus (Tunariu \& Reavey, 2007).

\section{Correlates with variables of sexuality}

The study of boredom within the field of sexuality gives special emphasis to risky sexual behaviors and hypersexuality. In this instance, boredom proneness showed positive correlations with both greater variety of sexual activities and greater number of sexual partners in men but only with greater variety of sexual activities in women (Zuckerman, Bone, Neary, Mangelsdorff, \& Brustman, 1972). Other studies found boredom proneness to predict solitary sexual behavior (masturbation and viewing pornography) in men and women (Gana, Trouillet, Martin, \& Toffart, 2001) as well as in hypersexual men who have sex with men online (Chaney \& Blalock, 2006). Boredom was also specifically identified as a predictor of risky sexual behavior for adolescents (Donohew et al., 2000; Greene, Krcmar, Walters, Rubin, \& Hale, 2000), gay men (Bancroft et al., 2003), and heterosexual men (Bancroft et al., 2004). In addition, boredom was positively correlated with hypersexual behavior in male patients with diverse sexual orientations (Reid, Garos, \& Carpenter, 2011), men who have sex with men (Downing Jr, Antebi, \& Schrimshaw, 2014), heterosexual men (Kraus, Rosenberg, Martino, Nich, \& Potenza, 2017), as well as in women (Zlot, Goldstein, Cohen, \& Weinstein, 2018). However, the link between boredom and hypersexuality is not fully established (de Oliveira \& Carvalho, 2020). Boredom proneness was also positively 
correlated with sexual boredom (Watt \& Ewing, 1996). Moreover, boredom was suggested as an important motive for the termination of marital relationships (Gigy \& Kelly, 1993) and pointed as an indirect mediating variable for predicting willingness to commit future infidelity (Gillen, 2013). In addition, boredom was positively correlated with infidelity in general (Brand, Markey, Mills, \& Hodges, 2007).

A few studies have identified relationships between sexual boredom and other aspects of sexuality. Specifically, sexual boredom was negatively correlated with both sexual satisfaction and sexual desire/interest (Carvalheira, Træen, \& Štulhofer, 2014; Štulhofer, Buško, \& Brouillard, 2010) and positively correlated with responsive sexual desire (Štulhofer, Carvalheira, \& Træen, 2013), masturbation (Carvalheira, Træen, \& Štulhofer, 2015; Zamboni \& Crawford, 2003) and hypersexuality (Klein, Jurin, Briken, \& Štulhofer, 2015; Štulhofer, Jelovica, \& Ružić, 2008; Štulhofer, Jurin, \& Briken, 2016). Furthermore, sexual boredom in long-term relationships was negatively correlated with sexual novelty (M. N. Rosa et al., 2019). Contrarily, individuals with low levels of sexual boredom and high levels of sex-positive traits (erotophilia, sensation seeking, sexual sensation seeking, sexual assertiveness, sex drive, sex frequency, sexual self-esteem, self-esteem, and openness to experience) reported higher levels of sexual novelty in their romantic relationships (Matthews et al., 2018).

\section{Sexual boredom and gender}

Previous research indicated boredom trait and sexual boredom are more prevalent in men when compared to women (e.g. Polly, Vodanovich, Watt, \& Blanchard, 1993; Tunariu \& Reavey, 2007; Watt \& Ewing, 1996). Explanations for sexual boredom in men are often framed within evolutionary psychology (e.g. Buss \& Schmitt, 1993). This view argues sexual boredom in men would be a manifestation of their reproductive promiscuity strategy, i.e. the tendency of males who have reached 
sexual satiation with one female to experience a restoration of mating behavior in the presence of a novel female (see Dewsbury, 1981). No explanation for sexual boredom in women is offered within this framework.

\section{Current study}

Past research on sexual boredom suggests relationships with a few sexuality aspects, including sexual desire, sexual satisfaction, and hypersexuality. Some studies also indicate the presence of a relationship between boredom proneness and solitary sexual behaviors, risky sex, and hypersexuality, and there is compelling evidence on the relationship between boredom proneness and sensation seeking. However, most studies on these topics are correlational and do not allow establishing a theory of sexual boredom. The existing theories regarding sexual boredom tend to focus on men's motivations underlying their sexual behavior, and do not offer alternative explanations for sexual boredom in women. The current study uses a data-driven approach to characterize groups of self-identified men and women in respect to sexual boredom. Our aim was to explore how sexual boredom emerges in non-clinical populations of both men and women, and how it translated to these individuals' sexuality and relationships. More precisely, this study intended to determine whether there were distinct groups of men and women experiencing sexual boredom and how those groups differed in other aspects of sexuality, specifically in sexual excitation, sexual desire (solitary, partner, and attractive person related), sexual pleasure, sexual satisfaction (ego and partner related), and sexual sensation seeking, as well as in boredom proneness. Findings will help identifying how different levels of sexual boredom manifest in groups of people with varying personalities, sexual motivations, and enjoyment of sex.

\section{Method}

\section{Participants}


The sample of this study consisted of 1021 participants aged 18 to 75 years old. Of these, $72.4 \%$ were self-identified women $(n=739)$ and $27.6 \%$ were self-identified men $(n=282)$. Of the total participants, 7 self-identified as transgender, and 2 preferred not to say. The sample average age was $32.68(S D=8.79)$. Participants were Portuguese speakers living in Portugal (88\%), Brazil (5.2\%), and other countries (6.8\%), of which 91.7\% had Portuguese nationality, $6.1 \%$ Brazilian nationality, and 2.2\% other nationality. A large majority of $89.7 \%$ participants $(n=912)$ were educated to a university level. Participants self-identified as heterosexual (80.7\%), lesbian/gay (7\%), bisexual (9.3\%), pansexual (2.8\%), and 3 participants (0.3\%) self-identified as other/preferred not to say. In regards to relationship status, $51.3 \%$ of the participants were married or cohabiting $(n=518), 23.9 \%$ were dating without cohabiting $(n=242)$, $23.1 \%$ did not have a relationship $(\mathrm{n}=234), 0.8 \%$ were in consensual non-monogamies $(\mathrm{n}=8), 0.2 \%$ reported having occasional sex $(n=2)$, and $0.7 \%$ reported other type of relationships $(\mathrm{n}=7)$.

\section{Measures}

\section{Boredom Proneness Scale (BPS).}

The BPS (Farmer \& Sundberg, 1986) is a self-report measure which consists of 28 true-false items designed to assess the trait or tendency for individuals to experience boredom. The authors reported a satisfactory level of internal consistency (Cronbach's alpha $=.79)$. Other authors chose to apply a 7-point Likert scale ranging from 1 (I totally disagree) to 7 (I totally agree) to BPS items with Cronbach's alpha coefficients ranging from .79 to .83 (cf. Mercer \& Eastwood, 2010). Most factor structure studies of the BPS agree on the presence of two factors (see Vodanovich \& Watt, 2016 for a review). One cluster seems to reflect the presence of low levels of perceived 
environmental stimulation (external stimulation). The other cluster seems to reflect the inability of people to create interesting activities for themselves (internal stimulation). The Portuguese version of BPS (Martins, 2012) comprises 26 only items (items 15 and 17 of the original version were excluded due to poor loadings) and uses a 7-point Likert scale. This version showed good reliability for total score (Cronbach's alpha $=.83$ ), and for internal stimulation (Cronbach alpha $=.88=$ ), and acceptable reliability for external stimulation (Cronbach alpha $=.69)$.

\section{Sexual Boredom Scale (SBS).}

The SPS (Watt \& Ewing, 1996) is an 18-item self-report measure of the tendency to experience boredom with sexual aspect of one's life. The SBS was designed for sexually active non-psychiatric populations. Responses are given on a 7-point Likert scale ranging from 1 (strongly disagree) to 7 (strongly agree) with higher scores reflecting higher sexual boredom. It comprises two subscales of 9 items each, 'Sexual Monotony' and 'Sexual Stimulation'. The first refers to sexual routine and tedium (e.g., Sex frequently becomes an unexciting and predictable routine) whilst the second to aspects of sexual excitement and constraint (e.g. I would not stay in a relationship that was sexually dull). The authors report high internal consistency reliability for total score across samples (Cronbach's alpha $=.92-.95$ ). The Portuguese adaptation of the SBS also demonstrated good reliability (Cronbach's alpha $=.93$ ), but revealed an unidimensional factor structure and three items were removed due to low loadings (Pechorro, Figueiredo, et al., 2015). In the current study, the Cronbach alpha was also .93.

\footnotetext{
Sexual Sensation Seeking Scale (SSSS).
} 
The SSSS (Kalichman \& Rompa, 1995) is an unidimensional self-report scale of 10 items designed to assess sexual sensation seeking, the need to have new and varied sexual experiences, taking physical and social risks to enhance sexual sensation. Items range from 1 (strongly disagree) to 4 (strongly agree). The authors report good internal consistency (Cronbach's alpha $=.81$ ). The Portuguese version of SSSS (Pechorro, Pascoal, et al., 2015) demonstrated good reliability (Cronbach's alpha $=.74)$. In this study Cronbach's alpha was .71.

\section{New Sexual Satisfaction Scale (NSSS).}

The NSSS (Štulhofer et al., 2010) is a 20 item scale consists of two dimensions of 10 items each that assess ego-centered sexual satisfaction and partner/sexual activity centered sexual satisfaction. Items range from 1 (not at all satisfied) to 5 (extremely satisfied). The scale was simultaneously validated for Croatia and United States. The authors report good internal consistency across samples for total score (Cronbach's alpha $=.94-.96)$, ego-centered sexual satisfaction (Cronbach's alpha $=.91-.93$ ), and partner-centered sexual satisfaction (Cronbach's alpha $=.91-.94)$. The Portuguese version presented Cronbach's alpha of .96 for total score, .95 for ego-centered sexual satisfaction, and .94 for partner-centered sexual satisfaction (Pechorro, Almeida, et al., 2015). In the current study, the Cronbach alpha was .95 for total score, 93 for egocentered sexual satisfaction, and .93 for partner/sexual activity centered sexual satisfaction.

\section{Sexual Desire Inventory-2 (SDI-2).}

The SDI-2 (Spector, Carey, \& Steinberg, 1996) is a self-report measure consisting in 14 items to assess sexual desire in two dimensions, dyadic sexual desire 
and solitary sexual desire. Items are answered in a 9-point scale ranging from 0 (no desire) to 8 (strong desire). In the authors' validation studies both factors present good levels of internal consistency (Cronbach's alpha $=.86$ for dyadic sexual desire and Cronbach's alpha $=.96$ for solitary sexual desire). A three-factor model of SDI-2 was recently proposed and splits up the dyadic sexual desire scale in 'partner related' and 'attractive person related' subscales (Moyano, Vallejo-Medina, \& Sierra, 2017). The Portuguese version of SDI-2 (Peixoto et al., 2018) presented Cronbach's alpha of .90 for total score, Cronbach's alpha of .91 for solitary sexual desire, and Cronbach's alpha of .88 for dyadic sexual desire. Results for the three-factor version also showed good Cronbach's alpha coefficients for the new subscales proposed by Moyano et al. (2017), with a value of .88 for dyadic sexual desire partner related subscale, and .88 for the dyadic sexual desire attractive person related subscale. The current study showed a Cronbach's alpha of .89 for total score, of .92 for solitary sexual desire, of .86 for partner dyadic sexual desire, and of .86 for attractive person dyadic sexual desire.

\section{Sexual Pleasure Scale (SPS).}

The SPS (Sanchez, Crocker, \& Boike, 2005) is a self-report measure of sexual pleasure with three items assessing the extent to which individuals perceive sexual intercourse, sexual activities and sexual intimacy as pleasurable. Items are presented in a 7-point Likert scale ranging from -3 (not pleasurable at all) to 3 (very pleasurable) with higher scores indicating greater satisfaction and pleasure. The authors reported good internal consistency with a value for Cronbach's alpha of .84. The Portuguese version of SPS (Pascoal, Sanchez, Raposo, \& Pechorro, 2016) uses a scale ranging from 1 (not pleasurable at all) to 7 (very pleasurable) and showed high level of internal consistency with value for Cronbach's alpha of .94. Total scores range from 3 to 21 
with higher scores translating higher sexual pleasure. Cronbach's alpha was .85 in the current study.

\section{Sexual Inhibition and Sexual Excitation Scales (SIS/SES).}

The SIS/SES (Janssen, Vorst, Finn, \& Bancroft, 2002) is a 45 item measure of sexual excitation and sexual inhibition with female and male versions. This study only uses the Sexual Excitation Scale (SES) where items describe a series of situations hypothetically leading to sexual arousal due to non-threatening potentially sexual exciting situations (e.g. When I think of a very attractive person, I easily become sexually aroused). Participants score in a 4-point Likert scale ranging from 1 (strongly agree) 4 (strongly disagree) indicating their typical response to the stimuli described. The original SES version has good levels of internal consistency (Cronbach's alpha $=$ .89). The Portuguese version of SIS/SES showed high internal consistency levels for SES (20 items: Cronbach's alpha $=.92)$ presenting adequate internal consistency. In this study Cronbach's alpha for SES was .90 for women, and .87 for men.

\section{Procedure}

Participants were recruited via email and social media snowballing and through the official channels of XXXX University. The study was also advertised in the University's SexLab webpage. To maximize and diversify this convenience sample some social media influencers also promoted the study in their platforms. All the advertisements displayed the survey link where a general description of context and purpose was provided followed by informed consent. The description included authorship, affiliations, and funding sources in addition to conditions of participating and the primary author's email contact for any questions or concerns. Participants were 
required to agree to terms and conditions and provide informed consent before moving forward with answering the questionnaire. After completing the study all participants could opt to provide theirs emails for further information on results as well as to leave any comment felt necessary. This study was approved by the Ethics Committee of XXXX University.

Responses were scrutinized for repeated entries and invalid responses. Even though conditions for participating emphasized participants needed to be at least 18year-old, some participants stated to be underage and their data was therefore excluded.

\section{Data analyses}

Data analyses were performed according to the following four steps: (1) Descriptive statistics were examined to the overall distributions of the self-report measures (internal boredom, external boredom, sexual boredom, sexual sensation seeking, excitation, solitary sexual desire, partner sexual desire, attractive person sexual desire, ego sexual satisfaction, partner sexual satisfaction, sexual pleasure); (2) A gender-stratified cluster analysis was used for classifying the subgroups based on the extent of our variables of interest; and (3) Analysis Of Variance (ANOVA) and chisquare of association tests were carried out to examine potential differences on age, relationship status and sexual orientation, among the subgroups (clusters) for both men and women. Cluster analysis was chosen due to be an appropriate method for grouping individual actions into patterns of behavior by determining which responses co-occurred (P. J. Rosa, Morais, Gamito, Oliveira, \& Saraiva, 2016), and allowing answering our research question. A two-step clustering algorithm was chosen due to its efficacy in large datasets by automatically determining the optimal number of clusters (Zhang, Ramakrishnan, \& Livny, 1996). The log-likelihood distance measure was applied for 
clustering and the Schwarz's Bayesian Criterion (BIC) was used for the selection of the optimal number of clusters. The silhouette measure of cohesion and separation was used for assessing overall clustering quality. The average silhouette measure ranges from 0 to 1 , indicating larger values more distinct clusters. The clustering quality model is assumed to be fair when the average silhouette value is at least .20 (Kaufman \& Rousseeuw, 1990). A noise handling of $30 \%$ was used as criterion for outlier removal (Gamito et al., 2016). Our analyses were performed on IBM-SPSS 25 and all tests of statistical significance were conducted at a 'p' value of .05.

\section{Results}

\section{Patterns of sexual boredom in men}

In regards to men, a three cluster solution was reached $(\mathrm{BIC}=2119.72): 39.7 \%$ of the cases $(\mathrm{n}=112)$ were assigned to Cluster 1 , named low sexual boredom; $22.3 \%$ of the cases were assigned to Cluster $2(\mathrm{n}=63)$ named high sexual boredom with low sexual motivation; and $37.9 \%$ to Cluster $3(\mathrm{n}=103)$, named high sexual boredom with high sexual motivation as depicted in Figure 1. The ratio size (largest cluster: smallest cluster) was 1.78. According to Kaufman and Rousseeuw (1990), the overall clustering quality was fair with an average silhouette of .30.

Cluster 1 (low sexual boredom) was characterized by men reporting low sexual boredom, low boredom proneness, low sexual motivation (sexual excitation and sexual desire), and high hedonic value (sexual satisfaction and sexual pleasure). Participants in Cluster 2 (high sexual boredom with low sexual motivation) reported high boredom proneness, low sexual motivation, and low hedonic value. Finally, participants in Cluster 3 (high sexual boredom with high sexual motivation), displayed higher sexual 
sensation seeking, higher sexual motivation, and higher hedonic value. Descriptive findings can be found in Figure 1.

Insert Figure 1 about here

\section{Patterns of sexual boredom in women}

In relation to women, three clusters were also found $(\mathrm{BIC}=2252.20): 41.4 \%$ were assigned to Cluster 1, low sexual boredom $(n=306), 29.0 \%$ to Cluster 2 , moderate sexual boredom $(n=214)$, and $29.5 \%$ of the cases $(n=218)$ were assigned to Cluster 3, high sexual boredom. One outlier $(0.1 \%)$ was identified as it could not fit into any cluster previously described. The ratio size was 1.76 . The overall clustering quality was fair with an average silhouette of .20. (Kaufman \& Rousseeuw, 1990).

Women with low sexual boredom (Cluster 1), presented low boredom proneness, low sexual motivation, and high hedonic value. Participants with moderate sexual boredom (Cluster 2), displayed higher sexual sensation seeking, higher sexual motivation, and higher hedonic value. Women with high sexual boredom (Cluster 3), shown high boredom proneness, low sexual motivation, and low hedonic value. See Figure 2 for descriptive findings. 


\section{Clusters comparison by gender}

After the three-cluster solution was found, we examined whether three relevant variables related to sexual behavior (age, relationship status, and sexual orientation) differed significantly among clusters for both men and women. Results revealed no statistically significant differences on age across clusters neither in men $[F(2,275)=$ $0.34, \mathrm{p}=.708]$ nor in women $[F(2,735)=0.16, \mathrm{p}=.855]$. As concerned to the relationship status, the categories "consensual non-monogamies" $(0.8 \%)$, "other type of relationships" $(0.7 \%)$ and "occasional sex" $(0.2 \%)$ were excluded from analysis because were residual categories. Chi-square results did not reveal a relationship between relationship status and the clusters in men $\chi 2(8)=7.85, \mathrm{p}=.448$. However, a significant association between the relationship status and the found clusters in women $\chi 2(8)=55.19, \mathrm{p}<.001$. A more detailed analysis showed that the Cluster 1 (low sexual boredom) had a higher percentage of married or cohabiting participants $\left(\mathrm{Z}_{a d j}=4.20\right)$ than participants with no relationship $\left(\mathrm{Z}_{a d j}=-6.10\right)$. Conversely, the Cluster 2 (moderate sexual boredom) had a higher percentage of participants with no relationship $\left(Z_{a d j}=5.2\right)$ than married or cohabiting participants $\left(\mathrm{Z}_{a d j}=-4.00\right)$. In addition, the

Cluster 3 (high sexual boredom) presented a lower percentage of participants that were dating with no cohabitation $\left(\mathrm{Z}_{a d j}=-2.00\right)$. Regarding sexual orientation the categories “other $(0.2 \%)$ " and "preferred not to say" $(0.1 \%)$ were considered residual categories $(<.1 \%)$ and therefore excluded from chi-square analyses. Results showed no relationship between sexual orientation and found clusters in men $\chi 2(6)=5.85, p=$ .440. Though, in women, a significant association between the sexual orientation and clusters was found $\chi 2(6)=20.65, p=.002$. A detailed analysis indicated that Cluster 1 (low sexual boredom) had a higher percentage of heterosexual participants $\left(\mathrm{Z}_{a d j}=3.80\right)$ than bisexual participants $\left(\mathrm{Z}_{a d j}=-3.30\right)$. On other hand, we found the opposite pattern 
for Cluster 2 (moderate sexual boredom), that is, a higher percentage of bisexual participants $\left(\mathrm{Z}_{a d j}=3.30\right)$ than heterosexual participants $\left(\mathrm{Z}_{a d j}=-2.80\right)$. Cluster 3 (high sexual boredom) showed no significant percentage differences between sexual orientation. For means and standard deviations for men and women's three cluster solution, see Table 1.

Insert Table 1 about here

\section{Discussion}

This study focused on sexual boredom in men and women, including aspects of personality (boredom proneness and sexual sensation seeking), sexual motivation (sexual excitation and sexual desire), and hedonic value (sexual satisfaction and sexual pleasure), and explored possible associations between these variables and the participants' relationship status and sexual orientation. Men and women were analyzed separately. Our cluster analysis revealed a three-cluster solution for both men and women. Although exhibiting relevant gender differences, clusters for men and women showed similar trends: a group experiencing lower sexual boredom and two groups experiencing sexual boredom (from moderate to high). As our cluster analyses further revealed, the groups of men and women with low sexual boredom presented low boredom proneness, low sexual motivation, and high hedonic value of sexual relationships. One group of men and one group of women presenting with sexual boredom (high sexual boredom in men, and moderate sexual boredom in women) displayed higher sexual sensation seeking, higher sexual motivation, and higher hedonic 
value. The group of men and the group of women dealing with higher sexual boredom, presented high boredom proneness, low sexual motivation, and low hedonic value. Yet, this group of women showed higher levels of sexual desire for attractive people, while experiencing moderate solitary sexual desire and low sexual desire for partner. On the other hand, the men in this group presented low levels of sexual desire for attractive people and for solitary sexual desire, and very low sexual desire for partner. Moreover, our findings indicate no significant association between relationship status and sexual orientation for men, whilst for women there were significant associations regarding these aspects. Below we discuss these differences in detail.

Our findings suggest individuals experiencing low levels of sexual boredom may be less prone to boredom and display lower sexual motivation. Previous research relates sexual boredom with boredom proneness (Watt \& Ewing, 1996) and with low sexual desire (Carvalheira et al., 2014), which aligns with our findings. Although a few studies found negative correlations between sexual boredom and sexual satisfaction (Carvalheira et al., 2014; Štulhofer et al., 2010), our participants showing low levels of sexual boredom showed high levels of sexual satisfaction and sexual pleasure. Maybe, individuals with less sexual motivation will invest less in sexual activity, reducing the chance of monotony/habituation to stimuli and therefore minimizing the likelihood of experiencing sexual boredom. At the same time, when these individuals engage in sexual activity, they perceive high hedonic value, which may in turn contribute to maintain their low levels of sexual boredom. Ultimately, our findings for these clusters suggest a match between the individual's internal states (sexual boredom and sexual desire) and the sexual stimulation they receive.

In both men and women, we found clusters of individuals experiencing sexual boredom together with high sexual sensation seeking. We did not find similar patterns 
in previous research, which indicated low sexual boredom and high sexual sensation seeking were related to sexual novelty in relationships (Matthews et al., 2018). As well, other research identified a positive relationship between boredom and sensation seeking and disinhibition (e.g Zuckerman, 1979), but the men and women in this group did not show high boredom proneness. In fact, the individuals in these clusters displayed high sexual motivation and high hedonic value associated with sexual activity, contradicting the studies showing that sexual boredom is linked to low sexual desire and low sexual satisfaction (Carvalheira et al., 2014; Štulhofer et al., 2010). Possibly, some individuals who tend to be sexually bored are individuals who are more disinhibited and activate sexual sensation seeking behaviors upon arousal, or vice-versa, but without necessarily feelings less bored sexually. According to the dual-control model, sexual arousal and associated behavior depend on the balance between sexual excitation and sexual inhibition (e.g. Bancroft \& Jansen, 2006). These individuals may experience high excitation and little inhibition and, consequently, activate sexual sensation seeking. On the other hand, may present fewer inhibitory mechanisms, increasing the likelihood of sexual sensation seeking, and leading to high excitation, as previous research suggested high sensation seekers are more responsive to strong or novel stimulation than low sensation seekers (Smith, Davidson, Smith, Goldstein, \& Perlstein, 1989). These findings may have implications for the study of sexual risk taking and hypersexuality. Furthermore, these groups presented high sexual boredom for men but only moderate sexual boredom for women, suggesting sexual sensation seeking may prevent high sexual boredom in women but not in men.

Finally, clusters of high sexual boredom in men and women showed simultaneously high boredom proneness, low sexual motivation, and low hedonic value. These findings support previous research, which postulates the relationship between 
sexual boredom and boredom trait (Watt \& Ewing, 1996), and with low sexual desire and low sexual satisfaction (Carvalheira et al., 2014; Štulhofer et al., 2010). Potentially, these men and women experience high sexual boredom because they display a boredom prone personality, take little pleasure or satisfaction from sexual activity, and consequently have lower sexual motivation, i.e., sexual excitation and sexual desire. We argued elsewhere that low sexual motivation can be a consequence of sexual boredom, as well as a defining feature of sexual boredom (article in press). Interestingly, these clusters did not show that sexual boredom activates sexual desire for an attractive person for men but showed it does for women. These findings do not sustain the assumption that men who get sexually bored would restore their mating behavior with a novel female as predicted by evolutionary theorists (e.g. Buss \& Schmitt, 1993; Dewsbury, 1981). In fact, our data suggest the sexually bored women, but not the sexually bored men, display high sexual desire for an attractive person while experiencing low sexual desire for a partner, explicitly contradicting these perspectives. Previous qualitative research with women indicates over-familiarity with partner and with their sexual activity leads to the waning of female sexual desire (Sims \& Meana, 2010). Perhaps some women are more sensitive to partnered sexual monotony and/or sexual frustration than men and may use fantasy with attractive others to safely manage sexual boredom, as sexual fantasies are safe (Zurbriggen \& Yost, 2004). Although evolutionary theory and research postulates men are more inclined to fantasize with anonymous and multiple sexual partners, whilst women are more inclined to fantasize with familiar and close-bonded partners (Ellis \& Symons, 1990; Wilson, 1997), recent research is suggesting this effect maybe smaller than generally thought, and likely to be influenced by sex role expectations rather than by sociobiological mechanisms (Fisher, 
Moore, \& Pittenger, 2012). Nevertheless, this area still requires much exploration in future research.

Our analysis showed women in the low sexual boredom spectrum were more likely to be married or cohabiting, whilst women with moderate sexual boredom were more likely to not be in relationships and less likely to be married/cohabiting. This seems to contradict research indicating relationship duration is linked to decreases in sexual desire in women (Murray \& Milhausen, 2012), as one would expect for married or cohabiting individuals. However, findings are in line with previous research indicating women who are married or cohabiting have greater odds of being sexually active and sexually satisfied than those who are not (Thomas, Hess, \& Thurston, 2015). Moreover, women experiencing low sexual boredom were more likely to be heterosexuals, whilst women experiencing moderate sexual boredom were more likely to be bisexuals. Bisexuality was previously related to elevated sexual sensation seeking and sexual excitability (Stief, Rieger, \& Savin-Williams, 2014), similarly to our group of women experiencing moderate sexual boredom, which also presented higher levels of sexual sensation seeking and sexual excitation. As for women presenting with high sexual boredom, these were less likely to be dating with not cohabitation, that is, more related to married or cohabiting status, which matches what could be expected from previous research. Cluster comparisons did not show any significant associations of relationship status and sexual orientation in the men's clusters. Together these findings suggest relationship status, and, to some extent, sexual orientation may be impinging in women's experiences of sexual boredom. However, this is an area still requiring extensive research, considering no other studies explored these aspects.

\section{Limitations and future directions}


This study intended to identify and characterize subgroups of individuals experiencing varying degrees of sexual boredom. Some limitations of the present study should also be considered. First, it could be asserted that the results obtained were based on information gathered via online survey from a convenience Portuguese community sample and therefore we are unable to extrapolate our findings to the general population. Second, we used self-report measures of sexual behavior. Even though selfdeception can impact on self-ratings, this bias can be especially pronounced in the case of general or trait judgments of performance which is not the case here. Future studies could use both self-reports and other more objective measures (e.g. ). Third, despite the silhouette coefficient is considered a good Internal measure for clusters validation, one disadvantage is related to the assessment of global clustering characteristics only. In future, more sophisticated methods using the gap statistic (Tibshirani, Walther, \& Hastie, 2001), for instance, may provide a more solid evidence to corroborate the number of clusters we found in our study. Forth, it must be taken into account that this is a cross-sectional study and, thus, the associations observed between the variables studied in cannot be considered as causal relationships. Therefore, longitudinal studies are required to analyze the sexual boredom over time.

However, we believe this study adds important insights on the possible nature of sexual boredom and its diverse presentations. Future research could focus on clarifying the role of individual and relationship factors underpinning sexual boredom, such as the existence of psychopathology (e.g. depression, anxiety), or the impact of relationship duration and dyadic adjustment, and consequences for sexual risk taking and hypersexuality. As well, further studies could investigate which protective factors may be preventing sexual boredom in the individuals who report no or low sexual boredom.

\section{Conclusions}


Our findings support the existence of individual variability in sexual boredom in men and women. Individuals experiencing low levels of sexual boredom seem less prone to boredom trait, display low sexual motivation, and enjoy high hedonic value in sex, whilst individuals dealing with high sexual boredom seem boredom prone, display low sexual motivation, and perceive low hedonic value in sex. Both men and women from these two groups present similar patterns, apart from sexual desire for attractive others, which was high for women in the high sexual boredom group but low for the men in this group. A third group presented high sexual sensation seeking, high sexual motivation, and high hedonic value, with the women of this group experiencing moderate sexual boredom and men high sexual boredom, suggesting sexual sensation seeking may prevent high levels of sexual boredom in women but not in men. These findings have implications for couples dealing with sexual problems and, potentially, for sexual risk taking. 


\section{References}

Bancroft, J., \& Jansen, E. (2006). The dual-control model: The role of sexual inhibition \& sexual excitation in sexual arousal and behavior. In E. Jansen (Ed.), The Psychophysiology of Sex. Bloomington, IN: Indiana University Press.

Bancroft, J., Janssen, E., Carnes, L., Goodrich, D., Strong, D., \& Long, J. S. (2004). Sexual activity and risk taking in young heterosexual men: The relevance of sexual arousability, mood, and sensation seeking. Journal of Sex Research, 41(2), 181-192. doi:10.1080/00224490409552226

Bancroft, J., Janssen, E., Strong, D., Carnes, L., Vukadinovic, Z., \& Long, J. S. (2003). Sexual risktaking in gay men: The relevance of sexual arousability, mood, and sensation seeking. Archives of Sexual Behavior, 32(6), 555-572. doi:10.1023/A:1026041628364

Berlyne, D. E. (1970). Novelty, complexity, and hedonic value. Perception \& Psychophysics, 8(5), 279-286. doi:10.3758/BF03212593

Brand, R. J., Markey, C. M., Mills, A., \& Hodges, S. D. (2007). Sex differences in self-reported infidelity and its correlates. Sex Roles, 57(1-2), 101-109. doi:10.1007/s11199-007-92215

Bruursema, K., Kessler, S. R., \& Spector, P. E. (2011). Bored employees misbehaving: The relationship between boredom and counterproductive work behaviour. Work \& Stress, 25(2), 93-107. doi:10.1080/02678373.2011.596670

Buss, D. M., \& Schmitt, D. P. (1993). Sexual strategies theory: an evolutionary perspective on human mating. Psychological review, 100(2), 204. doi:10.1037/0033-295x.100.2.204

Carvalheira, A. A., Træen, B., \& Štulhofer, A. (2014). Correlates of men's sexual interest: a cross-cultural study. The Journal of Sexual Medicine, 11(1), 154-164. doi:10.1111/jsm.12345

Carvalheira, A. A., Træen, B., \& Štulhofer, A. (2015). Masturbation and pornography use among coupled heterosexual men with decreased sexual desire: How many roles of masturbation? Journal of Sex \& Marital Therapy, 41(6), 626-635. doi:10.1080/0092623X.2014.958790

Chaney, M. P., \& Blalock, A. C. (2006). Boredom proneness, social connectedness, and sexual addiction among men who have sex with male internet users. Journal of Addictions \& Offender Counseling, 26(2), 111-122. doi:10.1002/j.2161-1874.2006.tb00012.x

Chaney, M. P., \& Chang, C. Y. (2005). A trio of turmoil for Internet sexually addicted men who have sex with men: Boredom proneness, social connectedness, and dissociation. Sexual Addiction \& Compulsivity, 12(1), 3-18. doi:10.1080/10720160590933671

de Oliveira, L., \& Carvalho, J. (2020). The link between boredom and hypersexuality: A systematic review. The Journal of Sexual Medicine, 17(5), 994-1004. doi:10.1016/j.jsxm.2020.02.007

Dewsbury, D. A. (1981). Effects of novelty of copulatory behavior: The Coolidge effect and related phenomena. Psychological Bulletin, 89(3), 464. doi:doi.org/10.1037/00332909.89.3.464

Donohew, L., Zimmerman, R., Cupp, P. S., Novak, S., Colon, S., \& Abell, R. (2000). Sensation seeking, impulsive decision-making, and risky sex: Implications for risk-taking and design of interventions. Personality and Individual Differences, 28(6), 1079-1091. doi:10.1016/S0191-8869(99)00158-0

Downing Jr, M. J., Antebi, N., \& Schrimshaw, E. W. (2014). Compulsive use of Internet-based sexually explicit media: Adaptation and validation of the Compulsive Internet Use Scale (CIUS). Addictive Behaviors, 39(6), 1126-1130. doi:10.1016/j.addbeh.2014.03.007

Ellis, B. J., \& Symons, D. (1990). Sex differences in sexual fantasy: An evolutionary psychological approach. The Journal of Sex Research, 27(4), 527-555. doi:10.1080/00224499009551579 
Fahlman, S. A., Mercer-Lynn, K. B., Flora, D. B., \& Eastwood, J. D. (2013). Development and validation of the multidimensional state boredom scale. Assessment, 20(1), 68-85. doi:10.1177/1073191111421303

Farmer, R., \& Sundberg, N. D. (1986). Boredom proneness--the development and correlates of a new scale. Journal of Personality Assessment, 50(1), 4-17. doi:10.1207/s15327752jpa5001_2

Fenichel, O. (1951). On the psychology of boredom. In D. Rapaport (Ed.), Organization and pathology of thought (pp. 349-361). New York, NY: Columbia University Press.

Fisher, T. D., Moore, Z. T., \& Pittenger, M.-J. (2012). Sex on the Brain?: An Examination of Frequency of Sexual Cognitions as a Function of Gender, Erotophilia, and Social Desirability. The Journal of Sex Research, 49(1), 69-77. doi:10.1080/00224499.2011.565429

Gamito, P. S., Morais, D. G., Oliveira, J. G., Brito, R., Rosa, P. J., \& de Matos, M. G. (2016). Frequency is not enough: Patterns of use associated with risk of Internet addiction in Portuguese adolescents. Computers in Human Behavior, 58, 471-478. doi:https://doi.org/10.1016/j.chb.2016.01.013

Gana, K., \& Akremi, M. (1998). L'échelle de Disposition à l'Ennui (EDE): Adaptation française et validation du Boredom Proneness Scale (BP). L'année Psychologique, 98(3), 429-450. doi:10.3406/psy.1998.28576

Gana, K., Trouillet, R., Martin, B., \& Toffart, L. (2001). The relationship between boredom proneness and solitary sexual behaviors in adults. Social Behavior and Personality: An International Journal, 29(4), 385-389. doi:10.2224/sbp.2001.29.4.385

Gigy, L., \& Kelly, J. B. (1993). Reasons for divorce: Perspectives of divorcing men and women. Journal of Divorce \& Remarriage, 18(1-2), 169-188. doi:10.1300/J087v18n01_08

Gillen, N. (2013). I'm bored, what else is out there? Testing how relational boredom leads to willingness to commit infidelity. (Doctoral Dissertation), Carleton University, Retrieved from https://curve.carleton.ca/system/files/etd/114930f2-2155-43eb-83c67754a0e3a469/etd pdf/de4241fe83394ebd5590c90373ecf5b1/gillenimboredwhatelseisouttheretestinghowrelational.pdf

Greene, K., Krcmar, M., Walters, L. H., Rubin, D. L., \& Hale, L. (2000). Targeting adolescent risktaking behaviors: the contributions of egocentrism and sensation-seeking. Journal of Adolescence, 23(4), 439-461. doi:10.1006/jado.2000.0330

Hill, A., \& Perkins, R. E. (1985). Towards a model of boredom. British Journal of Psychology, 76(2), 235-240. doi:10.1111/j.2044-8295.1985.tb01947.x

Janssen, E., Vorst, H., Finn, P., \& Bancroft, J. (2002). The Sexual Inhibition (SIS) and Sexual Excitation (SES) Scales: I. Measuring sexual inhibition and excitation proneness in men. Journal of Sex Research, 39(2), 114-126. doi:10.1080/00224490209552130

Kalichman, S. C., \& Rompa, D. (1995). Sexual sensation seeking and sexual compulsivity scales: Validity, and predicting HIV risk behavior. Journal of Personality Assessment, 65(3), 586-601. doi:10.1207/s15327752jpa6503_16

Kaufman, L., \& Rousseeuw, P. (1990). Finding groups in data: An introduction to cluster analysis. New York: John Wiley \& Sons.

Klein, V., Jurin, T., Briken, P., \& Štulhofer, A. (2015). Erectile dysfunction, boredom, and hypersexuality among coupled men from two European countries. The Journal of Sexual Medicine, 12(11), 2160-2167. doi:/10.1111/jsm.13019

Kraus, S. W., Rosenberg, H., Martino, S., Nich, C., \& Potenza, M. N. (2017). The development and initial evaluation of the pornography-use avoidance self-efficacy scale. Journal of Behavioral Addictions, 6(3), 354-363. doi:10.1556/2006.6.2017.057

Leary, M. R., Rogers, P. A., Canfield, R. W., \& Coe, C. (1986). Boredom in interpersonal encounters: Antecedents and social implications. Journal of Personality and Social Psychology, 51(5), 968. doi:10.1037/0022-3514.51.5.968 
Martins, A. I. (2012). Tédio na adolescência: estudo de adaptação e validação da" Boredom Proneness Scale" junto de uma amostra de adolescentes portugueses. (Masters Thesis), ISCTE - Instituto Universitário de Lisboa, Lisbon, Portugal.

Matthews, S. J., Giuliano, T. A., Rosa, M. N., Thomas, K. H., Swift, B. A., Ahearn, N. D., . . Mills, M. M. (2018). The battle against bedroom boredom: Development and validation of a brief measure of sexual novelty in relationships. The Canadian Journal of Human Sexuality, 27(3), 277-287. doi:10.3138/cjhs.2017-0041

Mercer, K. B., \& Eastwood, J. D. (2010). Is boredom associated with problem gambling behaviour? It depends on what you mean by 'boredom'. International Gambling Studies, 10(1), 91-104. doi:10.1080/14459791003754414

Mikulas, W. L., \& Vodanovich, S. J. (1993). The essence of boredom. The Psychological Record, 43(1), 3.

Moyano, N., Vallejo-Medina, P., \& Sierra, J. C. (2017). Sexual desire inventory: Two or three dimensions? The Journal of Sex Research, 54(1), 105-116. doi:10.1080/00224499.2015.1109581

Moynihan, A. B., Igou, E. R., \& van Tilburg, W. A. (2017). Boredom Increases Impulsiveness. Social Psychology. doi:10.1027/1864-9335/a000317

Murray, S. H., \& Milhausen, R. R. (2012). Sexual desire and relationship duration in young men and women. Journal of Sex \& Marital Therapy, 38(1), 28-40. doi:10.1080/0092623X.2011.569637

Pascoal, P. M., Sanchez, D., Raposo, C. F., \& Pechorro, P. (2016). Initial validation of the Sexual Pleasure Scale in clinical and non-clinical samples of partnered heterosexual people. The Journal of Sexual Medicine, 14(5), 1408-1413. doi:10.1016/j.jsxm.2016.06.010

Pechorro, P. S., Almeida, A. I., Figueiredo, C. S., Pascoal, P. M., Vieira, R. X., \& Jesus, S. N. (2015). Validação portuguesa da Nova Escala de Satisfação Sexual. Revista Internacional de Andrología, 13(2), 47-53. doi:10.1016/j.androl.2014.10.003

Pechorro, P. S., Figueiredo, C. S., Almeida, A. I., Pascoal, P. M., Maroco, J., \& Jesus, S. N. (2015). Adaptação portuguesa da Escala de Aborrecimento Sexual. Revista Internacional de Andrología, 13(3), 86-91. doi:10.1016/j.androl.2014.11.002

Pechorro, P. S., Pascoal, P. M., Figueiredo, C. S., Almeida, A. I., Vieira, R. X., \& Jesus, S. N. (2015). Portuguese validation of the Sexual Sensation Seeking Scale. Revista Internacional de Andrología, 13(4), 125-130. doi:10.1016/j.androl.2014.11.003

Peixoto, M. M., Gomes, H., Correia, A., Pires, I., Pereira, T., \& Machado, P. P. (2018). Translation and validation of the Portuguese version of the Sexual Desire Inventory-2: assessing gender differences. Sexual and Relationship Therapy, 1-14. doi:10.1080/14681994.2018.1472374

Perkins, R. E., \& Hill, A. (1985). Cognitive and affective aspects of boredom. British Journal of Psychology, 76(2), 221-234. doi: 10.1111/j.2044-8295.1985.tb01946.x

Polly, L. M., Vodanovich, S. J., Watt, J. D., \& Blanchard, M. J. (1993). The effects of attributional processes on boredom proneness. Journal of Social Behavior and Personality, 8(1), 123.

Reid, R. C., Garos, S., \& Carpenter, B. N. (2011). Reliability, validity, and psychometric development of the Hypersexual Behavior Inventory in an outpatient sample of men. Sexual Addiction \& Compulsivity, 18(1), 30-51. doi:10.1080/10720162.2011.555709

Rosa, M. N., Matthews, S. A., Giuliano, T. A., Thomas, K. H., Swift, B. A., \& Mills, M. M. (2019). Encouraging erotic variety: Identifying correlates of, and strategies for promoting, sexual novelty in romantic relationships. Personality and Individual Differences, 146, 158-169. doi:10.1016/j.paid.2019.04.009

Rosa, P. J., Morais, D., Gamito, P., Oliveira, J., \& Saraiva, T. (2016). The Immersive Virtual Reality Experience: A Typology of Users Revealed Through Multiple Correspondence Analysis Combined with Cluster Analysis Technique. Cyberpsychology, Behavior, and Social Networking, 19(3), 209-216. doi:10.1089/cyber.2015.0130 
Sanchez, D. T., Crocker, J., \& Boike, K. R. (2005). Doing gender in the bedroom: Investing in gender norms and the sexual experience. Personality and Social Psychology Bulletin, 31(10), 1445-1455. doi:10.1177/0146167205277333

Sims, K. E., \& Meana, M. (2010). Why did passion wane? A qualitative study of married women's attributions for declines in sexual desire. Journal of Sex \& Marital Therapy, 36(4), 360-380. doi:10.1080/0092623X.2010.498727

Smith, B. D., Davidson, R. A., Smith, D. L., Goldstein, H., \& Perlstein, W. (1989). Sensation seeking and arousal: Effects of strong stimulation of electrodermal activation and memory task performance. Personality and Individual Differences, 10(6), 671-679. doi:10.1016/0191-8869(89)90226-2

Spector, I. P., Carey, M. P., \& Steinberg, L. (1996). The Sexual Desire Inventory: Development, factor structure, and evidence of reliability. Journal of Sex \& Marital Therapy, 22(3), 175-190. doi:10.1080/00926239608414655

Stief, M. C., Rieger, G., \& Savin-Williams, R. C. (2014). Bisexuality is associated with elevated sexual sensation seeking, sexual curiosity, and sexual excitability. Journal of Personality and Individual Differences, 66, 193-198. doi:10.1016/j.paid.2014.03.035

Štulhofer, A., Buško, V., \& Brouillard, P. (2010). Development and bicultural validation of the new sexual satisfaction scale. Journal of Sex Research, 47(4), 257-268. doi:10.1080/00224490903100561

Štulhofer, A., Carvalheira, A. A., \& Træen, B. (2013). Is responsive sexual desire for partnered sex problematic among men? Insights from a two-country study. Sexual and Relationship Therapy, 28(3), 246-258. doi:10.1080/14681994.2012.756137

Štulhofer, A., Jelovica, V., \& Ružić, J. (2008). Is early exposure to pornography a risk factor for sexual compulsivity? Findings from an online survey among young heterosexual adults. International Journal of Sexual Health, 20(4), 270-280. doi:10.1080/19317610802411870

Štulhofer, A., Jurin, T., \& Briken, P. (2016). Is high sexual desire a facet of male hypersexuality? Results from an online study. Journal of Sex \& Marital Therapy, 42(8), 665-680. doi:10.1080/0092623X.2015.1113585

Thomas, H. N., Hess, R., \& Thurston, R. C. (2015). Correlates of sexual activity and satisfaction in midlife and older women. The Annals of Family Medicine, 13(4), 336-342. doi:10.1370/afm.1820

Tunariu, A. D., \& Reavey, P. (2003). Men in love: Living with sexual boredom. Sexual and Relationship Therapy, 18(1), 63-94. doi:10.1080/1468199031000061272

Tunariu, A. D., \& Reavey, P. (2007). Common patterns of sense making: A discursive reading of quantitative and interpretative data on sexual boredom. British Journal of Social Psychology, 46(4), 815-837. doi:10.1348/014466607X177669

Vodanovich, S. J., \& Kass, S. J. (1990). A factor analytic study of the boredom proneness scale. Journal of Personality Assessment, 55(1-2), 115-123. doi:10.1080/00223891.1990.9674051

Vodanovich, S. J., \& Watt, J. D. (2016). Self-report measures of boredom: An updated review of the literature. The Journal of Psychology, 150(2), 196-228. doi:10.1080/00223980.2015.1074531

Watt, J. D., \& Ewing, J. E. (1996). Toward the development and validation of a measure of sexual boredom. Journal of Sex Research, 33(1), 57-66. doi:10.1080/00224499609551815

Wilson, G. D. (1997). Gender differences in sexual fantasy: An evolutionary analysis. Personality and Individual Differences, 22(1), 27-31. doi:https://doi.org/10.1016/S0191-8869(96)00180-8

Zamboni, B. D., \& Crawford, I. (2003). Using masturbation in sex therapy: Relationships between masturbation, sexual desire, and sexual fantasy. Journal of Psychology and Human Sexuality, 14(2-3), 123-141. doi:10.1300/J056v14n02_08 
Zhang, T., Ramakrishnan, R., \& Livny, M. (1996). BIRCH: an efficient data clustering method for very large databases. . Paper presented at the ACM SIGMOD International Conference on Management of Data, New York, NY.

Zlot, Y., Goldstein, M., Cohen, K., \& Weinstein, A. (2018). Online dating is associated with sex addiction and social anxiety. Journal of Behavioral Addictions, 7(3), 821-826. doi:10.1556/2006.7.2018.66

Zuckerman, M. (1979). Beyond the optimal level of arousal. Hillsdale, NJ: Lawrence Erlbraum Associates.

Zuckerman, M., Bone, R. N., Neary, R., Mangelsdorff, D., \& Brustman, B. (1972). What is the sensation seeker? Personality trait and experience correlates of the Sensation-Seeking Scales. Journal of Consulting and Clinical Psychology, 39(2), 308. doi:10.1037/h0033398

Zurbriggen, E. L., \& Yost, M. R. (2004). Power, desire, and pleasure in sexual fantasies. Journal of Sex Research, 41(3), 288-300. doi:10.1080/00224490409552236 


\section{Cluster Comparison}

$\square 1$

low sexual boredom $\square 2$

hlgh sexeal boredam with low sxial motivatian
- 3

high sexeal baredam with high sexual mot/votian

Partner sexual desire

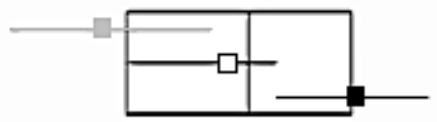

Attractive person sexual desire

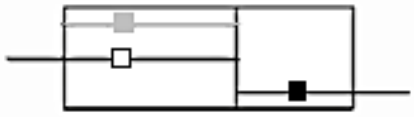

Excitation

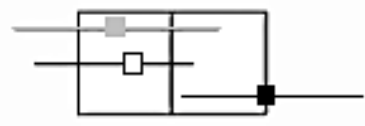

Ego sexual satisfaction

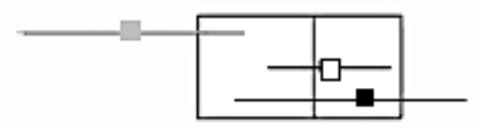

Sexual pleasure

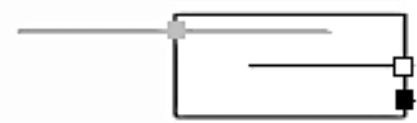

Partner sexual satisfaction

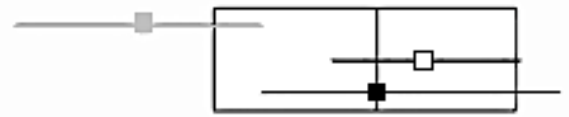

Sexual boredom

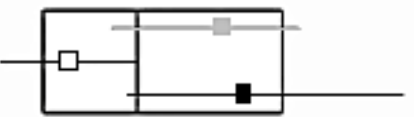

Sexual sensation seeking

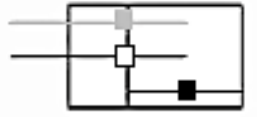

Solitary sexual desire

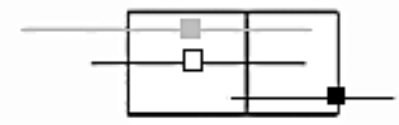

Internal boredom

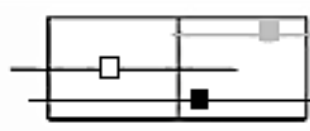

External boredom

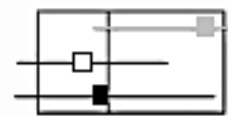


Figure 1. Cluster comparison in men sample. The small squares represent the median for each cluster. The line at the center represents the overall median. Note that input variables are sorted in descending order by prediction importance in estimating the clustering solution. 


\section{Cluster Comparison}

$\square 1 \quad \square 2 \square 3$

low sexial boredam maderate sexual baredam high sexual baredam

Ego sexual satisfaction

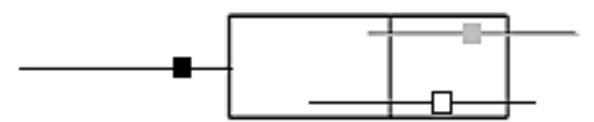

Attractive person sexual desire

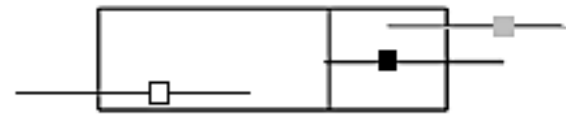

Sexual boredom

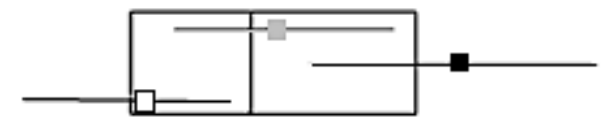

Partner sexual satisfaction

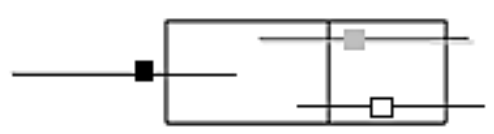

Excitation

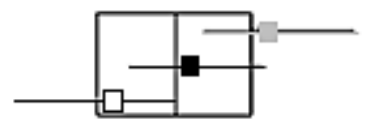

Solitary sexual desire

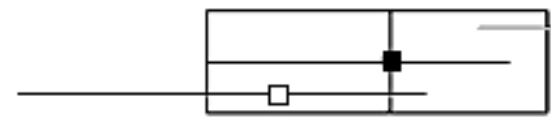

Partner sexual desire

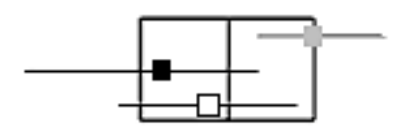

Internal boredom

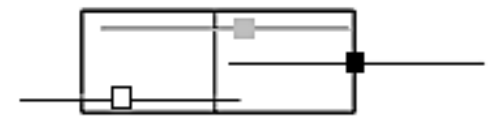

Sexual pleasure

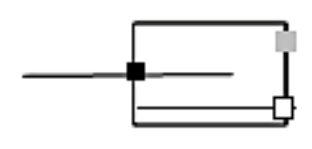

Sexual sensation seeking

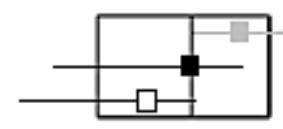

External boredom

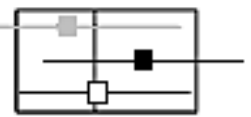


Figure 2. Cluster comparison in women sample. The small squares represent the median for each cluster. The line at the center represents the overall median. Note that input variables are sorted in descending order by prediction importance in estimating the clustering solution. 
Table 1. Centroids (means and standard deviations) of the three-cluster solution for men and women

\begin{tabular}{|c|c|c|c|c|c|c|}
\hline & \multicolumn{3}{|c|}{ Men } & \multicolumn{3}{|c|}{ Women } \\
\hline & $\begin{array}{c}\text { Low } \\
\text { sexual } \\
\text { boredom } \\
\text { (cluster 1) }\end{array}$ & $\begin{array}{l}\text { High sexual } \\
\text { boredom with } \\
\text { low sexual } \\
\text { motivation } \\
\text { (cluster } 2 \text { ) } \\
\end{array}$ & $\begin{array}{c}\text { High sexual } \\
\text { boredom with } \\
\text { high sexual } \\
\text { motivation } \\
\text { (cluster } 3 \text { ) } \\
\end{array}$ & $\begin{array}{c}\text { Low } \\
\text { sexual } \\
\text { boredom } \\
\text { (cluster 1) }\end{array}$ & 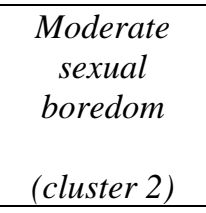 & $\begin{array}{c}\text { High } \\
\text { sexual } \\
\text { boredom } \\
\text { (cluster 3) }\end{array}$ \\
\hline & $M(S D)$ & $M(S D)$ & $M(S D)$ & $M(S D)$ & $M(S D)$ & $M(S D)$ \\
\hline Internal boredom & $\begin{array}{c}58.43(13.7 \\
6)\end{array}$ & $72.39(15.07)$ & $64.38(16.40)$ & $52.54(14.76)$ & $62.24(16.44)$ & $73.71(17.81)$ \\
\hline External boredom & $\begin{array}{c}20.24(4.51 \\
)\end{array}$ & $24.87(6.86)$ & $20.68(5.19)$ & $21.72(5.41)$ & $20.58(5.59)$ & $23.60(6.63)$ \\
\hline Sexual boredom & $\begin{array}{c}35.56(10.1 \\
7)\end{array}$ & $49.05(14.41)$ & $53.73(19.82)$ & $30.42(11.56)$ & $43.19(16.43)$ & $56.39(17.12)$ \\
\hline $\begin{array}{l}\text { Sexual sensation } \\
\text { seeking }\end{array}$ & $\begin{array}{c}26.23(2.40 \\
)\end{array}$ & $26.26(3.11)$ & $28.06(1.41)$ & $23.88(3.75)$ & $27.11(1.74)$ & $25.04(3.00)$ \\
\hline Ego sexual seeking & $\begin{array}{c}38.54(4.36 \\
)\end{array}$ & $29.86(7.28)$ & $39.37(7.64)$ & $38.48(6.36)$ & $40.14(6.03)$ & $26.44(7.87)$ \\
\hline $\begin{array}{l}\text { Partner sexual } \\
\text { satisfaction }\end{array}$ & $\begin{array}{c}35.05(6.38 \\
)\end{array}$ & $23.55(7.72)$ & $33.69(10.06)$ & $40.08(6.49)$ & $38.80(6.99)$ & $28.61(7.88)$ \\
\hline Sexual pleasure & $\begin{array}{c}19.99(1.35 \\
)\end{array}$ & $17.65(2.99)$ & $20.38(1.59)$ & 19.64(2.02) & $20.53(0.95)$ & $17.30(3.56)$ \\
\hline Partner sexual desire & $\begin{array}{c}40.88(5.05 \\
)\end{array}$ & $36.79(7.18)$ & $46.78(4.36)$ & $37.12(7.50)$ & $48.19(4.98)$ & $33.25(9.86)$ \\
\hline Solitary sexual desire & $\begin{array}{c}18.28(6.48 \\
)\end{array}$ & $17.94(6.35)$ & $22.84(5.15)$ & $12.27(7.88)$ & $22.56(4.83)$ & $15.42(7.79)$ \\
\hline $\begin{array}{l}\text { Attractive person } \\
\text { sexual desire }\end{array}$ & $8.86(3.13)$ & $9.07(2.75)$ & $12.62(2.27)$ & $4.80(3.21)$ & $10.51(2.66)$ & $8.31(3.74)$ \\
\hline Excitation & $\begin{array}{c}50.24(6.48 \\
)\end{array}$ & 49.79(7.00) & $58.34(6.95)$ & $43.71(7.87)$ & $55.83(7.07)$ & $50.26(7.06)$ \\
\hline
\end{tabular}

